\title{
SEER Summary Stage 2000
}

National Cancer Institute

\section{Source}

National Cancer Institute. SEER Summary Stage 2000. NCI Thesaurus. Code C160902.

A methodology published by the Surveillance, Epidemiology and End Results Program

(SEER) in 2000 to categ orize how far a cancer has spread from its point of origin. 